\title{
Effect of nitrogen levels on growth and development of three Lisianthus (Eustoma grandiflorum (Raf.) Shinn) cultivars pot-planted in Ho Chi Minh City
}

\author{
Duong T. T. Pham*, Duong H. A. Pham, Huong T. K. Nguyen, \\ Lieu T. Nguyen, \& Bao D. Nguyen \\ Faculty of Agronomy, Nong Lam University, Ho Chi Minh City, Vietnam
}

ARTICLE INFO
Research Paper
Received: March 02, 2020
Revised: April 15, 2020
Accepted: May 18, 2020
Keywords
Cultivars
Eustoma grandiflorum (Raf.) Shinn
Lisianthus
Nitrogen
Pot-planted
*Corresponding author
Pham Thi Thuy Duong
Email: pttduong@hcmuaf.edu.vn

\begin{abstract}
Lisianthus (Eustoma grandiflorum (Raf.) Shinn) is favored in decoration because of its long-lasting and colorful flowers. The objective of the experiment was to evaluate the effects of different levels of nitrogen on the growth and development of three Lisianthus cultivars pot-planted in Ho Chi Minh City. The experiment was laid out in split - plot design (SPD) with four levels of nitrogen $(3 ; 4 ; 5$; $6 \mathrm{~g} / \mathrm{pot}$ ) being the main factor and three lisianthus cultivars (Pink; Yellow; White/Purple) being the subordinate factor. Each pot was planted with one plantlet. The results indicated that plants applied with $4.0 \mathrm{~g}$ nitrogen per pot gave the best performance in plant height $(18.41 \mathrm{~cm})$ and number of leaves (24.08 leaves/plant) at 60 days after planted (DAP). The Pink cultivar reached the highest plant height $(19.92 \mathrm{~cm})$, number of leaves (43.53 leaves/plant) as well as number of flowers buds (12.31 buds/plant). The Pink cultivar, when applied with $4.0 \mathrm{~g}$ nitrogen/pot, gave the highest plant height $(21.38 \mathrm{~cm})$ at $60 \mathrm{DAP}$.
\end{abstract}

Cited as: Pham, D. T. T., Pham, D. H. A., Nguyen, H. T. K., Nguyen, L. T., \& Nguyen, B. D. (2020). Effect of nitrogen levels on growth and development of three Lisianthus (Eustoma grandiflorum (Raf.) Shinn) cultivars pot-planted in Ho Chi Minh City. The Journal of Agriculture and Development 19(4), 10-17. 


\title{
Ảnh hưởng của lượng đạm đến sinh trưởng và phát triển ba giống hoa cát tường (Eustoma grandiflorum (Raf.) Shinn) trồng chậu tại Thành phố Hồ Chí Minh
}

\author{
Phạm Thị Thùy Dương*, Phạm Hoàng Ánh Dương, Nguyễn Thị Kim Hương, \\ Nguyễn Thị Liễu \& Nguyễn Đức Bảo
}

Khoa Nông Học, Trường Đại Học Nông Lâm TP.HCM, TP. Hồ Chí Minh

\author{
THÔNG TIN BÀI BÁO \\ Bài báo khoa học \\ Ngày nhận: 02/03/2020 \\ Ngày chỉnh sửa: $15 / 04 / 2020$ \\ Ngày chấp nhận: 18/05/2020 \\ Từ khóa \\ Cây hoa cát tường \\ Đạm \\ Giống \\ Eustoma grandiflorum (Raf.) Shinn \\ Trồng chậu \\ *Tác giả liên hệ \\ Phạm Thị Thùy Dương \\ Email: pttduong@hcmuaf.edu.vn
}

\section{TÓM TẮT}

Cây hoa cát tường (Eustoma grandiflorum (Raf.) Shinn) được ưa chuộng trong trang trí bởi hoa bền đẹp và có màu sắc đa dạng. Mục tiêu của nghiên cứu là nhằm đánh giá được ảnh hưởng của các lượng đạm khác nhau đến sinh trưởng và phát triển của ba giống hoa cát tường trồng chậu tại Thành phố Hồ Chí Minh. Thí nghiệm hai yếu tố được bố trí theo kiểu lô phụ với lượng đạm $(3 ; 4 ; 5 ; 6$ $\mathrm{g} / \mathrm{chậu}$ ) là yếu tố chính và giống (màu hồng, màu vàng, màu trắng viền tím) là yếu tố phụ. Cây hoa cát tường khi được bón lượng đạm $4 \mathrm{~g} /$ chậu cho kết quả tốt nhất về chiều cao cây $(18,41 \mathrm{~cm})$ và số lá (24,08 lá/cây) tại thời điểm 60 ngày sau trồng (NST). Giống hoa cát tường màu hồng có chiều cao cây trung bình $(19,92 \mathrm{~cm})$, số lá (43,53 lá/cây), số nụ (12,31 nụ/cây) cao nhất so với các giống khác trong thí nghiệm. Giống hoa cát tường màu hồng được bón lượng đạm $4 \mathrm{~g} /$ chậu cho kết quả tốt nhất về chiều cao cây $(21,38$ $\mathrm{cm})$ tại thời điểm $60 \mathrm{NST}$.

\section{1. Đặt Vấn Đề}

Cây hoa cát tường (Eustoma grandiflorum (Raf.) Shinn) thuộc họ Gentianaceae, có nguồn gốc từ các vùng phía Nam Hoa Kỳ (Popa \& ctv., 2004; Jafari \& ctv., 2017). Hoa cát tường được thị trường ưa chuộng vì đa dạng về màu sắc, hình dạng và kích cỡ; đặc biệt vào các dịp lễ Tết, nhu cầu sử dụng hoa cát tường trong trang trí thường tăng cao (Nguyen \& ctv., 2019). Cây hoa cát tường có thể được sử dụng làm hoa cắt cành hoặc trồng chậu với nhiều màu sắc khác nhau như hồng, vàng, trắng, tím hoặc pha trộn nhiều màu (Asen \& ctv., 1986; Kunitake \& ctv., 1995).

Cây hoa cát tường là loại cây trồng ôn đới, thích hợp với nhiệt độ và cường độ ánh sáng thấp (Nguyen \& ctv., 2019). Hiện nay, cây hoa cát tường được trồng nhiều ở Lâm Đồng và một số tỉnh miền Bắc nước ta. Thành phố Hồ Chí Minh là địa phương có nhu cầu rất lớn về hoa kiểng, mặc dù sản lượng hoa trồng chậu (bao gồm cây hoa cát tường) ước tính đạt 6,7 triệu chậu/năm nhưng vẫn chưa đáp ứng đủ nhu cầu về cây trồng chậu của thành phố (HCMCPC, 2016). Cây hoa cát tường được trồng trên địa bàn thành phố là cơ hội thuận lợi để người trồng hoa nâng cao hiệu quả sản xuất nhờ tiết kiệm được chi phí vận chuyển.

Đối với sản xuất hoa kiểng, việc trồng ra chậu hoa đẹp đáp ứng thị hiếu của người tiêu dùng 
là điều cần thiết. Trong đó, đạm là yếu tố dinh dưỡng đa lượng thiết yếu và không thể thay thế đối với đời sống của thực vật, bao gồm cây hoa cát tường. Nhu cầu đạm của hầu hết cây trồng rất cao (Mengel \& ctv., 2001; Le, 2006). Cây trồng thiếu đạm trở nên còi cọc, vàng lá, sinh trưởng chậm. Trong khi đó, cây thừa đạm lại dễ bị vống, đồ ngã và nhạy cảm với sâu, bệnh hại. Đối với cây hoa cát tường được trồng trong chậu thì bộ rễ bị giới hạn ở một thể tích nhất định, do đó cần thiết phải lượng đạm thích hợp để cung cấp cho cây, giúp chậu cây trở nên cân đối. Ủy ban nhân dân tỉnh Lâm Đồng khuyến cáo bón $310 \mathrm{~kg} \mathrm{~N} / \mathrm{ha}$ cho cây hoa cát tường cắt cành được trồng ở mật độ 30.000 đến 32.000 cây/ha được thu hoạch hai lần (LDPPC, 2012), tương đương khoảng $5 \mathrm{~g} \mathrm{~N} /$ cây ở mỗi lần thu hoạch. Tuy nhiên, nghiên cứu về nhu cầu dinh dưỡng đạm cho cây hoa cát tường trồng chậu hiện nay còn rất hạn chế.

Bên cạnh dinh dưỡng, giống là một trong những yếu tố quan trọng đối với sản xuất nông nghiệp. Giống hoa cát tường rất đa dạng về màu sắc, hình dạng, có trên 200 giống hoa cát tường được bán phổ biến ở Hoa Kỳ và nhiều quốc gia khác (Harbaugh \& ctv., 2000). Mỗi giống cây trồng thường có những đặc điểm khác nhau về sinh trưởng, phát triển cũng như nhu cầu về dinh dưỡng. Việc nghiên cứu để tìm ra lượng đạm thích hợp cho một số giống hoa cát tường để giúp cây sinh trưởng, phát triển tốt, đồng thời tiết kiệm chi phí sản xuất là điều cần thiết.

\section{Vật Liệu và Phương Pháp Nghiên Cứu}

\subsection{Thời gian và địa điểm}

Thí nghiệm được thực hiện từ tháng 10/2019 đến 02/2020 tại Trại thực nghiệm Khoa Nông học, Trường Đại học Nông Lâm Thành phố Hồ Chí Minh.

\subsection{Vật liệu nghiên cứu}

Cây giống: Cây giống hoa cát tường được gieo từ hạt có đủ 6 lá thật, chiều cao 3,30 đến $3,75 \mathrm{~cm}$ không có triệu chứng của sâu, bệnh gây hại. Cây giống do công ty TNHH Đà Lạt Hasfarm cung cấp.

Giá thể: Giá thể bao gồm phân bò, mụn dừa, tro trấu và đất mặt được trộn theo công thức $30 \%$ phân bò $+40 \%$ mụn dừa $+20 \%$ tro trấu + $10 \%$ đất mặt (tính chất giá thể được trình bày ở
Bảng 1). Lượng giá thể được cho vào chậu tương ứng 1,2 kg/chậu. Phân bón gốc: Urea $(46,3 \% \mathrm{~N})$; Super lân Long Thành $\left(16,0 \% \mathrm{P}_{2} \mathrm{O}_{5}\right)$; Kali clorua $\left(60 \% \mathrm{~K}_{2} \mathrm{O}\right)$.

Chậu trồng: Có đường kính mặt $\mathrm{x}$ đường kính đáy $\mathrm{x}$ chiều cao $=18 \times 12 \times 18 \mathrm{~cm}$.

\subsection{Phương pháp nghiên cứu}

Thí nghiệm hai yếu tố được bố trí theo kiểu lô phụ (SPD), gồm 12 nghiệm thức và 3 lần lặp lại. Yếu tố chính gồm 4 lượng phân đạm: $3 ; 4 ; 5$ (Đối chứng - ĐC) và $6 \mathrm{~g} \mathrm{~N} /$ chậu. Yếu tố phụ gồm ba giống hoa cát tường: giống màu hồng, giống màu vàng và giống màu trắng viền tím.

Tổng số ô cơ sở: 36 ô; Số chậu trên mỗi ô cơ sở: 20 chậu/ô; Tổng số chậu thí nghiệm: 720 chậu; Số cây trên mỗi chậu: 1 cây/chậu; Diện tích thí nghiệm: $109,3 \mathrm{~m}^{2}$. Lượng phân nền: $3,0 \mathrm{~g} \mathrm{P}_{2} \mathrm{O}_{5}+$ $3,5 \mathrm{~g} \mathrm{~K}_{2} \mathrm{O} /$ chậu. Toàn bộ lượng lân bón vào giá thể trước khi trồng 15 ngày. Lượng đạm và kali được chia đều thành 10 lần bón, bón 7 ngày/lần và bắt đầu vào thời điểm $15 \mathrm{NST}$.

Các chỉ tiêu theo dõi bao gồm:

Chiều cao cây $(\mathrm{cm})$ : đo từ vết sẹo cặp lá dưới cùng đến đỉnh sinh trưởng của chồi cao nhất trên cây, định kì 15 ngày/ lần cho đến khi cây bắt đầu ra nụ.

Số lá (lá/ cây): đếm tất cả số lá thật trên cây, định kỳ 15 ngày/lần đến khi cây bắt đầu ra nụ. Lá thật được tính khi nhìn thấy rõ gốc lá và phiến lá.

Số nụ trên cây (nụ/cây): đếm tất cả các nụ hoa trên cây. Ghi nhận số liệu 1 lần ở thời điểm xuất vườn (85 NST).

Số hoa trên cây (hoa/ cây): đếm tất cả các hoa đã nở hoàn toàn trên cây. Hoa nở hoàn toàn được tính khi toàn bộ cánh hoa xòe ra và nhìn thấy rõ nhị hoa. Ghi nhận số liệu 1 lần ở thời điểm xuất vườn (85 NST).

Số liệu thu thập được tính toán bằng phần mềm Microsoft Excel; phân tích ANOVA, xếp hạng Duncan ở mức $\alpha=0,05$ bằng chương trình SAS 9.1.

\section{Kết Quả và Thảo Luận} 3.1. Kết quả phân tích giá thể trồng ba giống
hoa cát tường trong thí nghiệm

Kết quả phân tích đất ở Bảng 1 cho thấy giá thể được sử dụng để trồng cây hoa cát tường có 
Bảng 1. Kết quả phân tích giá thể trồng ba giống hoa cát tường trong thí nghiệm

\begin{tabular}{cccc}
\hline Chỉ tiêu & Đơn vị & Kết quả phân tích & Phương pháp \\
\hline $\mathrm{pH}_{\mathrm{KCl}}(1: 5)$ & 6,94 & $\mathrm{pH}$ & meter \\
$\mathrm{EC}(1: 5)$ & $\mathrm{mS} / \mathrm{cm}$ & 3,05 & EC meter \\
$\mathrm{C}$ hữu cơ & $\%$ & 14,227 & Tiurin \\
$\mathrm{N}$ tổng số & $\%$ & 0,391 & Kjeldalh \\
$\mathrm{C} / \mathrm{N}$ & $\%$ & 36,386 & \\
$\mathrm{P}_{2} \mathrm{O}_{5}$ tổng số & $\%$ & 0,375 & So màu \\
$\mathrm{K}_{2} \mathrm{O}$ tổng số & $\%$ & 0,412 & Quang kế ngọn lửa \\
$\mathrm{CEC}$ & $\mathrm{meq} / 100 \mathrm{~g}$ & 8,063 & Amoni axetat \\
Dung trọng & $\mathrm{g} / \mathrm{cm}^{3}$ & 0,612 & Ống đong kim loại \\
Tỉ trọng & $\mathrm{g} / \mathrm{cm}^{3}$ & 1,403 & Piknometer \\
Độ xốp & $\%$ & 56,379 & Phương pháp sấy \\
Ầm độ & $\%$ & 44,085 & \\
\hline
\end{tabular}

độ chua ở mức trung tính và không bị nhiễm mặn (Slavich \& Petterson, 1993). Giá thể sau khi ủ có hàm lượng $\mathrm{C}$ hữu cơ tổng số $(14,227 \%)$ và $\mathrm{C} / \mathrm{N}$ $(36,386 \%)$ cao cho thấy giá thể đang trong giai đoạn phân hủy. Các chất dinh dưỡng đạm, lân và kali tổng số đều ở mức cao. Trong khi đó, khả năng trao đổi cation CEC $(8,063 \mathrm{meq} / 100 \mathrm{~g})$ của giá thể ở mức thấp (Rayment \& Lyons, 2011), có thể do các chất dinh dưỡng được giải phóng ở dạng dễ tiêu trong giá thể không cao, vì vậy cần thiết phải bổ sung thêm các chất dinh dưỡng trong quá trình sinh trưởng và phát triển của cây hoa cát tường. Giá thể có độ xốp $(56,379 \%)$ và ẩm độ $(44,085 \%)$ ở mức trung bình.

\section{2. Ảnh hưởng của lượng đạm đến chiều cao cây của ba giống hoa cát tường}

Kết quả ở Bảng 2 cho thấy chiều cao cây của ba giống hoa cát tường khác biệt rất có ý nghĩa thống kê ở thời điểm 15 NST. Giống hoa cát tường màu hồng có chiều cao cây $(5,27 \mathrm{~cm})$ tốt nhất nhưng không khác biệt thống kê so với giống màu vàng; giống màu trắng viền tím có chiều cao cây $(4,34 \mathrm{~cm})$ thấp nhất. Tại thời điểm này, chiều cao của cây hoa cát tường khác biệt chủ yếu do đặc điểm của giống và không bị tác động bởi lượng phân đạm.

Ở thời điểm $30 \mathrm{NST}$, chiều cao cây hoa cát tường chịu ảnh hưởng bởi yếu tố lượng đạm và giống. Khi bón các lượng đạm $3 ; 4$ và $5 \mathrm{~g} /$ chậu cho cây hoa cát tường, chiều cao cây không khác biệt thống kê và cao hơn so với bón lượng đạm 6 $\mathrm{g} / \mathrm{chậu}$. Giống hoa cát tường màu hồng có chiều cao cây tốt nhất, đạt $6,76 \mathrm{~cm}$; trong khi giống màu vàng và màu trắng viền tím có chiều cao cây thấp nhất, lần lượt là 5,63 và $4,97 \mathrm{~cm}$. Tương tác giữa lượng đạm và giống không ảnh hưởng đến chiều cao cây hoa cát tường ở thời điểm này.

Tương tự, ở thời điểm 45 NST, lượng đạm và giống ảnh hưởng rõ rết đến chiều cao cây hoa cát tường. Cây hoa cát tường được bón lượng đạm $5 \mathrm{~g} /$ chậu cho chiều cao cây $(11,10 \mathrm{~cm})$ tốt nhất nhưng không khác biệt thống kê so với bón lượng đạm $4 \mathrm{~g} / \mathrm{chậu}(10,56 \mathrm{~cm})$, tuy nhiên khác biệt rất có ý nghĩa thống kê so với bón lượng đạm 3 và 6 $\mathrm{g} /$ chậu (lần lượt là 9,44 và $8,86 \mathrm{~cm}$ ). Giống hoa cát tường màu hồng có chiều cao tốt nhất, đạt $12,09 \mathrm{~cm}$ cao hơn so với hai giống còn lại trong thí nghiệm. Chiều cao của cây hoa cát tường ở thời điểm này không bị ảnh hưởng bởi tương tác giữa yếu tố lượng đạm và giống.

Ở thời điểm $60 \mathrm{NST}$, chiều cao cây hoa cát tường chịu ảnh hưởng của lượng đạm, giống và tương tác giữa hai yếu tố này. Chiều cao cây hoa cát tường khác biệt rất có ý nghĩa thống kê khi được bón các lượng đạm khác nhau. Lượng đạm $5 \mathrm{~g} /$ chậu cho kết quả chiều cao cây $(18,83 \mathrm{~cm})$ tốt nhất nhưng không khác biệt so với bón các lượng đạm 3 và $4 \mathrm{~g} /$ chậu (lần lượt là 18,41 và $18,16 \mathrm{~cm}$ ), tuy nhiên khác biệt rất có ý nghĩa thống kê so với bón $6 \mathrm{~g} / \mathrm{chậu}(13,89 \mathrm{~cm})$. Điều này cho thấy việc bón lượng đạm cao hơn nhu cầu có thể gây độc cho cây. Giống hoa cát tường màu hồng có chiều cao cây tốt nhất, đạt $19,92 \mathrm{~cm}$ và giống màu trắng viền tím có chiều cao cây thấp nhất $(14,04 \mathrm{~cm})$. Kết quả này cũng tương đồng với nghiên cứu của Nguyen \& ctv. (2019) trên giống hoa cát tường màu hồng khi cho biết chiều cao cây dao động từ 20,87 đến $36,57 \mathrm{~cm}$ ở thời điểm 55 NST. Giống hoa cát tường màu hồng khi được bón lượng đạm 


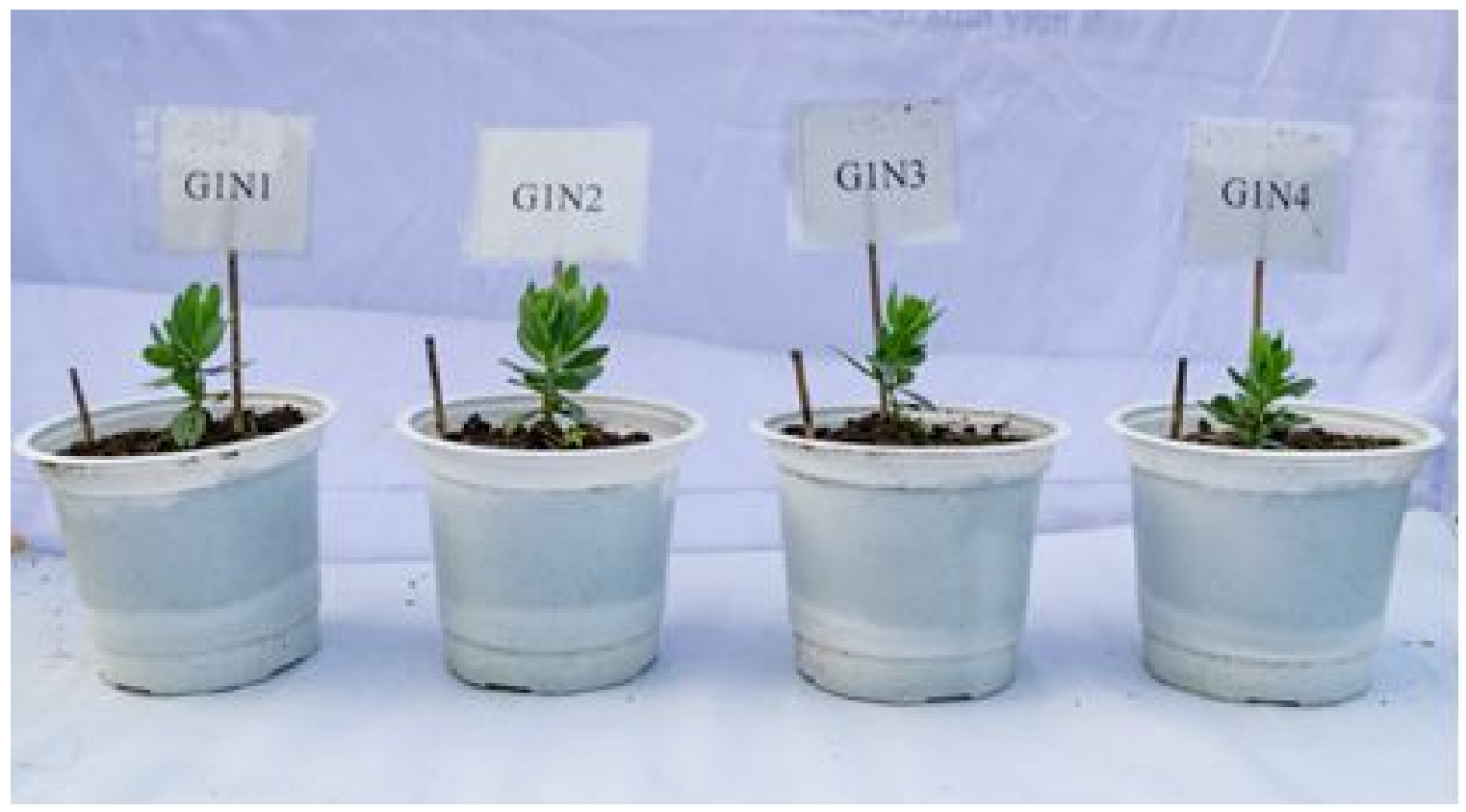

Hình 1. Số lá trên cây của giống hoa cát tường màu hồng được bón các lượng đạm khác nhau ở thời điểm 30 NST.

$5 \mathrm{~g} /$ chậu cho chiều cao cây tốt nhất đạt $23,07 \mathrm{~cm}$ nhưng không khác biệt thống kê so với bón lượng đạm $4 \mathrm{~g} / \mathrm{chậu}$, đạt $21,38 \mathrm{~cm}$. Như vậy, xét về hiệu quả kinh tế, việc bón lượng đạm $4 \mathrm{~g} /$ chậu có ưu thế hơn.

Nhìn chung, cây hoa cát tường được trồng chậu trong thí nghiệm có chiều cao cây thấp hơn rất nhiều so với cây hoa cát tường cắt cành được trồng ở các vùng có khí hậu mát mẻ (94 đến 126 cm) (Harbaugh \& ctv., 2000). Tuy nhiên, chiều cao cây hoa cát tường trong thí nghiệm cân đối so với kích thước chậu trồng.

\section{3. Ảnh hưởng của lượng đạm đến số lá của ba giống hoa cát tường}

Kết quả ở Bảng 3 cho thấy, số lá trên cây của ba giống hoa cát tường khác biệt rất có ý nghĩa thống kê ở tất cả các thời điểm theo dõi. Trong khi đó, lượng đạm chỉ tác động đến số lá trên cây hoa cát tường bắt đầu từ thời điểm $30 \mathrm{NST}$. Nhìn chung, tương tác giữa lượng đạm và giống không ảnh hưởng đến chỉ tiêu này.

Ở thời điểm 15 NST, số lá trên cây hoa cát tường khác biệt rất có ý nghĩa thống kê ở ba giống khác nhau. Giống hoa cát tường màu hồng có số lá trên cây $(9,50$ lá/cây) nhiều nhất nhưng không khác biệt thống kê so với giống màu vàng (8,60 lá/cây); giống màu trắng viền tím có số lá trên cây ít nhất (7,43 lá/cây).

Ở thời điểm $30 \mathrm{NST}$, yếu tố lượng đạm và giống tác động rõ rệt đến số lá trên cây hoa cát tường. Khi được bón lượng đạm $4 \mathrm{~g} /$ chậu, cây hoa cát tường có số lá trên cây nhiều nhất, đạt 16,40 lá/cây nhưng không khác biệt thống kê so với bón lượng đạm 3 và $5 \mathrm{~g} / \mathrm{chậu}$, tuy nhiên cao hơn so với bón lượng đạm $6 \mathrm{~g} / \mathrm{chậu}(10,62 \mathrm{~cm})$ (Hình 1). Điều này chứng tỏ nhu cầu đạm của cây hoa cát tường không vượt quá $6 \mathrm{~g} / \mathrm{chậu}$, nếu bón quá nhiều đạm cây có thể sinh trưởng chậm. Giống hoa cát tường màu hồng có số lá trên cây nhiều nhất, đạt 17,75 lá/cây, khác biệt rất có ý nghĩa thống kề so với hai giống còn lại trong thí nghiệm.

Ở thời điểm $45 \mathrm{NST}$, cây hoa cát tường được bón lượng đạm $4 \mathrm{~g} /$ chậu có số lá trên cây $(24,08$ lá/cây) nhiều nhất nhưng không khác biệt thống kê so với bón 3 và $5 \mathrm{~g} /$ chậu, tuy nhiên khác biệt so với bón lượng đạm $6 \mathrm{~g} / \mathrm{chậu} \mathrm{(17,60} \mathrm{lá/cây).}$ Giống hoa cát tường màu hồng có số lá trên cây (25,78 lá/cây) nhiều nhất nhưng không khác biệt thống kê so với giống màu vàng; giống trắng viền tím có số lá trên cây $(18,43$ lá/cây) thấp nhất.

Ở thời điểm $60 \mathrm{NST}$, số lá trên cây hoa cát 
Bảng 2. Ảnh hưởng của lượng đạm đến chiều cao cây $(\mathrm{cm})$ của ba giống hoa cát tường

\begin{tabular}{|c|c|c|c|c|c|}
\hline \multirow{2}{*}{ Thời điểm NST } & \multirow{2}{*}{ Lượng N (g/chậu) } & \multicolumn{3}{|c|}{ Giống (G) } & \multirow{2}{*}{$\mathrm{TB}(\mathrm{N})$} \\
\hline & & Hồng & Vàng & Trắng viền tím & \\
\hline \multirow{6}{*}{15} & 3 & 5,04 & 4,38 & 4,27 & 4,56 \\
\hline & 4 & 5,46 & 5,08 & 4,15 & 4,90 \\
\hline & $5(Đ C)$ & 5,53 & 5,01 & 4,22 & 4,92 \\
\hline & 6 & 5,06 & 4,60 & 4,73 & 4,80 \\
\hline & $\mathrm{TB}(\mathrm{G})$ & $5,27^{\mathrm{a}}$ & $4,77^{\mathrm{ab}}$ & $4,34^{\mathrm{b}}$ & \\
\hline & \multicolumn{5}{|c|}{$\mathrm{CV} \%)=9,69 ; \mathrm{FN}=1,11^{\mathrm{ns}} ; \mathrm{FG}=12,08^{* *} ; \mathrm{FN}^{*} \mathrm{G}=1,18^{\mathrm{ns}}$} \\
\hline \multirow{6}{*}{30} & 3 & 6,43 & 5,65 & 5,27 & $5,78^{\mathrm{ab}}$ \\
\hline & 4 & 7,03 & 6,21 & 5,23 & $6,16^{\mathrm{a}}$ \\
\hline & $5(Đ C)$ & 7,29 & 5,96 & 5,20 & $6,15^{\mathrm{a}}$ \\
\hline & 6 & 6,29 & 4,70 & 3,97 & $4,99^{\mathrm{b}}$ \\
\hline & TB (G) & $6,76^{\mathrm{a}}$ & $5,63^{\mathrm{b}}$ & $4,97^{\mathrm{b}}$ & \\
\hline & $\mathrm{CV}(\%)=13,01$ & $\mathrm{~N}=4,85^{*}$ & $; \mathrm{FG}=18$ & $9^{* *} ; \mathrm{FN}^{*} \mathrm{G}=0$ & $1^{\mathrm{ns}}$ \\
\hline \multirow{7}{*}{45} & 3 & 13,68 & 11,91 & 8,98 & $9,44^{\mathrm{bc}}$ \\
\hline & 4 & 15,25 & 11,84 & 8,40 & $10,56^{\mathrm{ab}}$ \\
\hline & $5(\mathrm{DC})$ & 14,73 & 11,92 & 9,32 & $11,10^{\mathrm{a}}$ \\
\hline & 6 & 11,14 & 8,67 & 6,22 & $8,86^{\mathrm{c}}$ \\
\hline & $\mathrm{TB}(\mathrm{G})$ & $12,09^{\mathrm{a}}$ & $9,89^{\mathrm{b}}$ & $7,98^{\mathrm{c}}$ & \\
\hline & $\mathrm{CV}(\%)=13,57 ; \mathrm{I}$ & $=6,01^{*}$ & $\mathrm{FG}=27$, & $7^{* *} ; \mathrm{FN}^{*} \mathrm{G}=0$ & $5^{\mathrm{ns}}$ \\
\hline & $\mathrm{CV}(\%)=13,01 ;$ & $\mathrm{N}=4,85^{*}$ & $; \mathrm{FG}=18$ & $39^{* *} ; \mathrm{FN}^{*} \mathrm{G}=0$ & $1^{\mathrm{ns}}$ \\
\hline \multirow{6}{*}{60} & 3 & $18,69^{\mathrm{bcd}}$ & $19,93^{\mathrm{bc}}$ & $15,87^{\text {ef }}$ & $18,16^{\mathrm{a}}$ \\
\hline & 4 & $21,38^{\mathrm{ab}}$ & $19,12 \mathrm{bcd}$ & $14,71^{\mathrm{f}}$ & $18,41^{\mathrm{a}}$ \\
\hline & $5(\mathrm{DC})$ & $23,07^{\mathrm{a}}$ & $18,51^{\text {cde }}$ & $14,93^{\mathrm{f}}$ & $18,83^{\mathrm{a}}$ \\
\hline & 6 & $16,52 \mathrm{def}$ & $14,53^{\mathrm{f}}$ & $10,63^{\mathrm{g}}$ & $13,89^{\mathrm{b}}$ \\
\hline & $\mathrm{TB}(\mathrm{G})$ & $19,92^{\mathrm{a}}$ & $18,02^{b}$ & $14,04^{\mathrm{c}}$ & \\
\hline & \multicolumn{5}{|c|}{$\mathrm{CV}(\%)=6,16 ; \mathrm{FN}=41,87^{* *} ; \mathrm{FG}=10,72^{* *} ; \mathrm{FN}^{*} \mathrm{G}=4,76^{*}$} \\
\hline
\end{tabular}

\footnotetext{
${ }^{\mathrm{a}-\mathrm{f}}$ Trong cùng một nhóm giá trị trung bình, các số có cùng ký tự đi kèm thể hiện sự khác biệt không có ý nghĩa thống kê; ns: không có khác biệt thống kê.
}

*: Khác biệt có ý nghĩa thống kê $\alpha=0,05,{ }^{* *}$ : khác biệt rất có ý nghĩa thống kê ở $\alpha=0,01$.

tường chịu ảnh hưởng của yếu tố lượng đạm và giống. Cây hoa cát tường được bón lượng đạm $4 \mathrm{~g} /$ chậu có số lá trên cây nhiều nhất, đạt 40,54 lá/cây nhưng không khác biệt thống kê so với bón lượng đạm 3 và $5 \mathrm{~g} / \mathrm{chậu}$. Cây hoa cát tường được bón lượng đạm $6 \mathrm{~g} /$ chậu có số lá trên cây it nhất, đạt 31,70 lá/cây. Giống hoa cát tường màu hồng có số lá trên cây nhiều nhất, đạt 43,53 lá/cây và ít nhất là giống màu trắng viền tím, đạt 29,92 lá/cây, chênh lệch 13,61 lá/cây. Kết quả này cũng tương đồng với nghiên cứu của Ahmad \& ctv. (2017) và Nguyen \& ctv. (2019).

\section{4. Ảnh hưởng của lượng đạm đến số nụ và số hoa của ba giống hoa cát tường}

Kết quả ở Bảng 4 cho thấy, số nụ trên cây của ba giống hoa cát tường khác nhau trong thì nghiệm thì khác biệt rất có ý nghĩa thống kê. Giống hoa cát tường màu hồng có số nụ trên cây
(12,31 nụ/cây) nhiều nhất, nhưng không khác biệt so với giống màu vàng $(10,84$ nụ/cây) và cao hơn so với giống màu trắng viền tím $(10,00$ nụ/cây). Yếu tố lượng đạm, tương tác giữa lượng đạm và giống không ảnh hưởng đến chỉ tiêu số nụ trên cây.

Kết quả ở Bảng 4 cũng cho thấy, sự khác biệt về số hoa của ba giống hoa cát tường dưới ảnh hưởng của bốn lượng đạm khác nhau trong thí nghiệm thì không có ý nghĩa thống kê. Số hoa trên cây dao động từ 4,43 đến 7,10 hoa/cây. Kết quả này cũng tương tự nghiên cứu của Nguyen \& ctv. (2019) khi cho biết số hoa trên cây hoa cát tường dao động trong khoảng 4,39 đến 7,53 hoa/cây. Điều này cho thấy, lượng phân đạm trong thí nghiệm không tác động đến quá trình hình thành nụ và nở hoa của ba giống cát tường trong thí nghiệm. 
Bảng 3. Ảnh hưởng của lượng đạm đến số lá (lá/cây) của ba giống hoa cát tường

\begin{tabular}{|c|c|c|c|c|c|}
\hline \multirow{2}{*}{ Thời điểm NST } & \multirow{2}{*}{ Lượng N (g/chậu) } & \multicolumn{3}{|c|}{ Giống (G) } & \multirow{2}{*}{$\mathrm{TB}(\mathrm{N})$} \\
\hline & & Hồng & Vàng & Trắng viền tím & \\
\hline \multirow{6}{*}{15} & 3 & 9,98 & 6,83 & 7,73 & 8,36 \\
\hline & 4 & 9,17 & 8,30 & 7,13 & 8,20 \\
\hline & $5(\mathrm{DC})$ & 9,17 & 7,73 & 7,07 & 7,99 \\
\hline & 6 & 9,52 & 11,54 & 7,78 & 9,61 \\
\hline & $\mathrm{TB}(\mathrm{G})$ & $9,50^{\mathrm{a}}$ & $8,60^{\mathrm{ab}}$ & $7,43^{\mathrm{b}}$ & \\
\hline & \multicolumn{5}{|c|}{$\mathrm{CV} \%)=16,40 ; \mathrm{FN}=2,66^{\mathrm{ns}} ; \mathrm{FG}=6,27^{* *} ; \mathrm{FN}^{*} \mathrm{G}=2,11^{\mathrm{ns}}$} \\
\hline \multirow{6}{*}{30} & 3 & 17,20 & 13,93 & 15,47 & $15,53^{\mathrm{a}}$ \\
\hline & 4 & 18,87 & 16,33 & 14,00 & $16,40^{\mathrm{a}}$ \\
\hline & $5(\mathrm{DC})$ & 17,97 & 15,43 & 13,87 & $15,76^{\mathrm{a}}$ \\
\hline & 6 & 16,97 & 7,57 & 7,33 & $10,62^{\mathrm{b}}$ \\
\hline & $\mathrm{TB}(\mathrm{G})$ & $17,75^{\mathrm{a}}$ & $13,32^{\mathrm{b}}$ & $12,67^{\mathrm{b}}$ & \\
\hline & \multicolumn{5}{|c|}{$\mathrm{CV} \%)=19,45 ; \mathrm{FN}=7,94^{* *} ; \mathrm{FG}=11,43^{* *} ; \mathrm{FN}^{*} \mathrm{G}=1,55^{\mathrm{ns}}$} \\
\hline \multirow{7}{*}{45} & 3 & 25,03 & 21,97 & 20,37 & $22,46^{\mathrm{a}}$ \\
\hline & 4 & 26,57 & 25,13 & 20,53 & $24,08^{\mathrm{a}}$ \\
\hline & $5(\mathrm{DC})$ & 26,83 & 22,97 & 19,00 & $22,93^{\mathrm{a}}$ \\
\hline & 6 & 24,70 & 14,30 & 13,80 & $17,60^{\mathrm{b}}$ \\
\hline & 6 & 16,97 & 7,57 & 7,33 & $10,62^{\mathrm{b}}$ \\
\hline & $\mathrm{TB}(\mathrm{G})$ & $25,78^{\mathrm{a}}$ & $21,09^{\mathrm{ab}}$ & $18,43^{b}$ & \\
\hline & \multicolumn{5}{|c|}{$\mathrm{CV} \%)=19,82 ; \mathrm{FN}=3,96^{* *} ; \mathrm{FG}=8,96^{* *} ; \mathrm{FN}^{*} \mathrm{G}=0,71^{\mathrm{ns}}$} \\
\hline \multirow{6}{*}{60} & 3 & 38,93 & 36,13 & 30,70 & $35,26^{\mathrm{ab}}$ \\
\hline & 4 & 49,33 & 40,37 & 31,93 & $40,54^{\mathrm{a}}$ \\
\hline & $5(\mathrm{DC})$ & 48,00 & 41,03 & 30,97 & $40,00^{\mathrm{a}}$ \\
\hline & 6 & 37,83 & 31,20 & 26,07 & $31,70^{\mathrm{b}}$ \\
\hline & TB (G) & $43,53^{\mathrm{a}}$ & $37,18^{b}$ & $29,92^{\mathrm{c}}$ & \\
\hline & \multicolumn{5}{|c|}{$\mathrm{CV} \%)=14,28 ; \mathrm{FN}=15,57^{* *} ; \mathrm{FG}=20,08^{* *} ; \mathrm{FN}^{*} \mathrm{G}=0,57^{\mathrm{ns}}$} \\
\hline
\end{tabular}

a-c Trong cùng một nhóm giá trị trung bình, các số có cùng ký tự đi kèm thể hiện sự khác biệt không có ý nghĩa thống kê.

ns: Không có khác biệt thống kê, ${ }^{* *}$ : khác biệt rất có ý nghĩa thống kê ở $\alpha=0,01$.

Bảng 4. Ảnh hưởng của lượng đạm đến số nụ (nụ/cây) và số hoa (hoa/cây) của ba giống hoa cát tường

\begin{tabular}{|c|c|c|c|c|c|}
\hline \multirow{2}{*}{ Chỉ tiêu theo dõi } & \multirow{2}{*}{ Lượng N (g/chậu) } & \multicolumn{3}{|c|}{ Giống (G) } & \multirow{2}{*}{$\mathrm{TB}(\mathrm{N})$} \\
\hline & & Hồng & Vàng & Trắng viền tím & \\
\hline \multirow{6}{*}{ Số nụ (nụ/cây) } & 3 & 12,10 & 11,07 & 10,23 & 11,13 \\
\hline & 4 & 14,47 & 11,43 & 10,63 & 12,18 \\
\hline & $5(\mathrm{DC})$ & 12,77 & 11,43 & 10,23 & 11,48 \\
\hline & 6 & 9,90 & 9,43 & 8,90 & 9,41 \\
\hline & $\mathrm{TB}(\mathrm{G})$ & $12,31^{\mathrm{a}}$ & $10,84^{\mathrm{ab}}$ & $10,00^{\mathrm{b}}$ & \\
\hline & $\mathrm{CV} \%)=17,33 ; \mathrm{FI}$ & $=1,15^{\mathrm{ns}}$ & $; \mathrm{FG}=$ & $47^{*} ; \mathrm{FN}^{*} \mathrm{G}=0$ & $7^{\mathrm{ns}}$ \\
\hline \multirow{6}{*}{ Số hoa (hoa/cây) } & 3 & 4,43 & 5,23 & 5,53 & 5,40 \\
\hline & 4 & 7,10 & 6,10 & 5,90 & 6,37 \\
\hline & $5(\mathrm{DC})$ & 6,47 & 5,77 & 5,43 & 5,89 \\
\hline & 6 & 5,77 & 5,43 & 5,33 & 5,51 \\
\hline & $\mathrm{TB}(\mathrm{G})$ & 6,19 & 5,63 & 5,55 & \\
\hline & \multicolumn{5}{|c|}{$\mathrm{CV} \%)=14,90 ; \mathrm{FN}=0,89^{\mathrm{ns}} ; \mathrm{FG}=1,96^{\mathrm{ns}} ; \mathrm{FN}^{*} \mathrm{G}=0,38^{\mathrm{ns}}$} \\
\hline
\end{tabular}

\footnotetext{
a-b Trong cùng một nhóm giá trị trung bình, các số có cùng ký tự đi kèm thể hiện sự khác biệt không có ý
} nghĩa thống kê.

ns : không có khác biệt thống kê, * : khác biệt có ý nghĩa thống kê ở $\alpha=0,05$. 


\section{Kết Luận}

Ba giống hoa cát tường khi được bón lượng đạm $4 \mathrm{~g} /$ chậu cho kết quả tốt nhất về chiều cao cây $(18,41 \mathrm{~cm})$ và số lá $(24,08$ lá/cây) tại thời điểm 60 NST. Giống hoa cát tường màu hồng có chiều cao cây trung bình $(19,92 \mathrm{~cm})$, số lá $(43,53$ lá/cây), số nụ (12,31 nụ/cây) cao nhất so với các giống khác trong thí nghiệm. Giống hoa cát tường màu hồng được bón lượng đạm $4 \mathrm{~g} /$ chậu cho kết quả tốt nhất về chiều cao cây $(21,38 \mathrm{~cm})$ tại thời điểm 60 NST.

\section{Lời Cam Đoan}

Chúng tôi cam đoan bài báo do nhóm tác giả thực hiện và không có bất kỳ mâu thuẫn nào giữa các tác giả.

\section{Tài Liệu Tham Khảo (References)}

Ahmad, H., Rahul, S., Mahbuba, S., Jahan, M. R., \& Uddin, A. F. M. J. (2017). Evaluation of Lisianthus (Eustoma grandiflorum) lines for commercial production in Bangladesh. International Journal of Business, Social And Scientific Research 5, 156-167.

Asen, S., Griesbach, R. J., Norris, C., \& Leonhardt, B. (1986). Flavonoids fron Eustoma flower petals. Phytochem 25, 2509-2513.

Harbaugh, B. K., Bell, M. L., \& Liang, R. (2000). Evaluation of forty-seven cultivars of Lisianthus as cut flowers. Hort Technology 10, 812-815.

HCMCPC (Ho Chi Minh City People's Committee) (2016). Decision No. 536/ QD-UBND February 5, 2016 on approving the flower growing program in the city in the period of 2016 - 2020. Ho Chi Minh City, Vietnam: Ho Chi Minh City People's Committee.

Jafari, R., Moieni, A., Karimzadeh, G., \& Movahedi, Z. (2017). In Vitro Propagation of Lisianthus (Eustoma grandiflorum). Journal of Plant Physiology and Breeding 7, 53-65.
Kunitake, H., Nakashima, T., Mori, K., Tanaka, M., \& Mii, M. (1995). Plant regeneration from mesophyll protoplasts of lisianthus (Eustoma grandiflorum) by adding activated charcoal into protoplast culture medium. Plant Cell, Tissue and Organ Culture 43, 5965 .

LDPPC (Lam Dong Province People's Committee) (2012). Decision No. 1251/QD-SNN dated December 13, 2012 on temporarily cultivation procedures for some local crops in Lam Dong Province. Lam Dong Province, Vietnam: Lam Dong Province People's Committee.

Le, V. D. (2006). Curriculum for soil fertility and fertilizer. Nong Lam University, Ho Chi Minh City, Vietnam.

Mengel, K., Kirkby, E. A., Kosegarten, H., \& Appel, T. (2001). Principles of plant nutrition. NewYork, America: Springer Nature Switzerland AG.

Nguyen, C. C, Bui, T. C., Nguyen, L. D., \& Le, T. L. (2019). Effect of substrates and floria fertilizer on growth and development of Lisianthus (Eustoma grandiflorum) pot-planted in Ho Chi Minh City. Report on scientific research topics, Nong Lam University, Ho Chi Minh City, Vietnam.

Popa, G., Balan, V., \& Plocon, C. (2004). Studies on the in-vitro culture of Lisianthus russellianus Hook. Buletinul Universitatii de Stiinte Agricole si Medicina Veterinara Cluj Napoca Seria Zootehnie si Biotehnologii 60, 319-322.

Rayment, G. E., \& Lyons, D. J. (2011). Soil chemical methods - Australasia. Victoria, Australia: SCIRO Publishing.

Slavich, P. G., \& Petterson, G.H. (1993). Estimating the critical conductivity of saturated paste extracts from 1:5 soil:water suspensions and texture. Australian Journal of Soil Research 31, 73-81. 